\title{
CRISTINA PARODI. Borges-Bioy en contexto. Una lectura guiada de H. Bustos Domecq
}

y B. Suárez Lynch. Pittsburgh: Borges Center; University of Pittsburgh, 2018. 443 pp. ISBN 978-0-9907292-4-2.

Ariscos. Díscolos. Una especie de animal huidizo como una anguila o, mejor aun, un lagarto que cuando creemos que logramos atraparlo se nos escapa dejándonos solo con la cola en la mano. Esos adjetivos y esas metáforas son los que me parece definen con alguna certeza la obra en colaboración de Borges y Bioy Casares atribuida a los autores ficticios Honorio Bustos Domecq y Benito Suárez Lynch. Lo abigarrado de las frases en el estilo de ambos heterónimos, plagadas de referencias culturales de distinta índole, hace que aun cuando el lector pueda decodificar algunas, permanezca la sensación de que el texto lo excede. De que siempre queda algo que nos falta identificar, algo en lo que no reparamos en ese momento, pero que aparecerá de un brinco como un saltimbanqui bromista en alguna próxima lectura. Esa condición barroca del estilo y la dificultad que acarrea se une a una distancia con el lector que es de otro orden, y es la distancia temporal con esas referencias, que, en el mejor de los casos, remiten al mundo contemporáneo de los textos y que en otros casos pueden llevar incluso a comienzos del siglo XX o finales del XIX.

Estos factores están muy bien señalados por Cristina Parodi en su libro. Probablemente sea esa la clave del lugar marginal que los textos de Bustos Domecq y Suárez Lynch ocupan en el canon literario; lo cierto es que este corpus no ha sido presa muy codiciada por la crítica ni por estudiantes en cursos específicos ni por lectores comunes. No obstante, existe una cadena de aportes previos por parte de la crítica académica que considero factible señalar acá. Especialistas como Andrés Avellaneda, IvánAlmeida, Gonzalo Moisés Aguilar, JaimeAlazraki, María Teresa Gramuglio, Mireya Camurati, Michel Lafon, Graciela Scheines, entre otros, han realizado interesantes avances sobre el tema. Es curioso que Parodi no mencione estos antecedentes, más aun cuando muchos de los elementos que ella devela ya están anticipados en esas contribuciones previas. De todos modos, el esfuerzo de Cristina Parodi en Borges-Bioy en contexto se presenta como el de saltar de lleno sobre el animal no domesticado y atraparlo, no para amansarlo, sino para desentrañar todas sus características. Y lo logra.

Este libro, resultado de un exhaustivo trabajo de investigación de años, logra ponerse a la altura del exceso que caracteriza al corpus estudiado. Dadas las dificultades señaladas en el primer párrafo de esta reseña, Parodi asume la necesidad de explicar cada una de las referencias que pueblan cada línea del abigarrado corpus Bustos Domecq-Suárez Lynch. La obra tiene, tal como la estudiosa señala, un carácter enciclopédico, que no solo se limita a definir los elementos sobre los que indaga, sino que propende a una expansión hacia los contextos socioculturales e históricos, de ahí el título.

$111 \frac{\text { Revista Iberoamericana, Vol. LXXXV, Núm. 269, Octubre-Diciembre 2019, }}{1341-1373}$ 
El libro se organiza en capítulos en cada uno de los cuales se analiza una obra de manera exhaustiva recorriendo sus párrafos y sus líneas. Con un ordenado modo de citación y sistema de nomenclaturas, el trabajo va atravesando cada uno de los cuentos de los autores ficticios, ofreciendo un detallado catálogo razonado de referencias tanto internas como externas. Vale decir, el minucioso recorrido da cuenta detallada de las características y representaciones de los recurrentes personajes que forman la comparsa literaria pergeñada por Borges y Bioy, así como de alusiones a hechos, costumbres, circunstancias, libros de la época o más antiguos que aparecen en los textos, que son aquí cuidadosamente explicadas. Quien tenga dudas o confusión acerca de las obras, los trabajos, la biografía incluso, y las tranformaciones de Gervasio Montenegro, Carlos Anglada, Mariana Ruiz Villalba, José Formento, Mario Bonfanti, entre otros personajes principales, así como de los secundarios que los rodean, o de los nuevos esperpentos que van a aparecer en Un modelo para la muerte (1946) o en Dos fantasías memorables (1946), encontrará en el trabajo de Parodi una completa reconstrucción que le permitirá despegar hacia interpretaciones posteriores. De la misma manera sucederá con la reconstrucción de época a partir de la decodificación de las aparentemente interminables referencias culturales de todo tipo.

Párrafo aparte merece el recorrido efectuado sobre Crónicas de Bustos Domecq (1967) y Nuevos cuentos de Bustos Domecq (1977). Porque si bien Seis problemas para don Isidro Parodi (1942) y Un modelo para la muerte ofrecen dificultad, la presencia de los mismos personajes, que entran y salen de un cuento a otro, así como la unidad dada por el género policial, constituyen un hilo conductor que permite al lector mantener un horizonte de referencias constante. Dos fantasias memorables, si bien aporta personajes diferentes e historias nuevas, diseñadas dentro del género fantástico y no policial, se mantiene más o menos en el mismo esquema compositivo. Las Crónicas y los Nuevos cuentos, en cambio, publicados más de veinte años después de aquellos y firmados con los nombres de los autores reales a diferencia de los tres primeros, presentan una organización narrativa totalmente diferente. Se trata aquí de pequeños relatos autónomos, con personajes totalmente nuevos y multiplicados y, que difieren en cada crónica-cuento, con un contenido mucho más abstracto que el de los tres primeros libros. Aquí, la lupa de la investigadora se hace más precisa para pasar de un microuniverso a otro.

El libro de Cristina Parodi, así, se presenta como un trabajo necesario para la continuidad de los estudios sobre la obra atribuida a Bustos Domecq y Suárez Lynch, e incluso de su lectura. Se trata de un material de consulta imprescindible para aquel que quiera adentrarse en el juego barroco del sentido, que se devela y se esconde, y disfrutarlo.

María del Carmen Marengo Universidad Nacional de Córdoba 